A paper presented at the Pittsfield Section Meet.

ing of the American Institute of Electrical

Engineers, Pittsfield, Mass., January 18,1912.

Copyright 1912. By A.I.E.E.

\title{
CENTRAL STATION ELECTRIC POWER FOR RAILROAD OPERATION
}

\section{BY FREDERICK DARLINGTON}

Every engineering operation seeks to accomplish some practical result, which is measured by its financial worth or capacity to earn money by saving labor in doing something useful. There are no exceptions to this, but in railroad work, which is the subject of this paper, we often have to look further and deeper for the full measure of worth, than is usual in any other matters with which I am familiar.

In the manufacture of cloth, for instance, the problem is simple, that is, make cloth of a desirable quality, at a minimum cost; likewise in making steel rails or bricks or paper, or any article of merchandise, there is a definite result to be attained and the final test of different methods is the cost and value of the product, which in such instances is readily determined. There is no such simple way to judge the merits of transportation work for it is far more complex than manufacturing or other lines of production. This is seen in the great diversity of rates and classifications under which railroad accommodations are sold. In freight business, for example, there are different rates for long hauls and for short hauls, for car loads and for part car loads and various classifications almost without limit. This diversity has not, as many people suppose, resulted primarily from a desire on the part of railroads to " charge what the traffic will bear," but rather from necessity caused by differences in transportation costs, combined with differences in the value of services rendered. It is not necessary to enlarge upon this, for 
we all know it would be fatal to the interests of both buyers and sellers of transportation to attempt to make a uniform rate for all freight transportation on a ton-mile basis, or on a uniform basis of distance hauled, or on any direct measure of transportation. An equitable rate for carrying a ton of wheat from Chicago to New York City has very little relation to an equitable rate for carrying a ton of wheat twenty miles from a farm to a grain elevator; likewise, there is very little relation between the cost per ton of transporting a carload of wheat and the cost on a single ton in a part carload lot, and short hauls and part carload lots may be quite as important in the aggregate as long hauls. What I want to bring out is not the value of the work done by the railroads, immense and necessary as it is, but rather to point out the need for still more and different railroad facilities, and to show that the use of electric power from central station plants will benefit railroads and at the same time benefit all other operations requiring power.

There is a wide field for improvement in railroad service that can be best accomplished with electric power, especially for local transportation. The statement has been made that the money expended in hauling freight by wagon to and from freight depots of one of the largest railroad systems in New England, is greater than the gross receipts of the railroad from its freight business, and I am inclined to believe that this will apply to other American railroads. It is certain that the cost of hauling freight by wagon to and from railroads is a heavy part of freight transportation. Also in passenger service the collection and distribution of passengers to and from railroad depots is a matter of large cost and has an important bearing on travel. This is evidenced by the work of electric interurban trolley roads, the favorite field of which is in the territory tributary to steam railroads, where they have in many places greatly facilitated the local collection and distribution of traffic. I will not enlarge upon this for it is well understood.

In comparing steam and electric power for railroads, the comparison should not be based on the relative cost of operating certain trains by steam and by electric motive power, but the comparison should be made between the best use of steam power considering the cost and value of the service rendered, compared with the best use of electric power, considering the cost and value of electric service. It follows from the wide difference in the nature of the two kinds of power, that the train weights, schedules, 
etc., and even the locations that are best for railroads employing steam power, will not always be best for electric power.

So far as distribution of power is concerned, independent of whether it is for railroads or for other purposes, it is demonstrated that wherever a large number of small powers are to be supplied in a limited territory it is more economical to distribute it by electricity than by any other known method. An example is seen in the case of textile mills, where power from steam engines or waterpowers was formerly generated at each mill and conveyed to various rooms and machines by series of shafts and belts. This plan has been widely superseded with electric drive whereby electricity is generated in a central plant supplying numerous mills and is used to operate motors for driving small groups of machines in each mill, or even for driving a separate motor for each machine. Likewise, in railroad work, electric motive power enables a profitable service to be rendered with greatly subdivided motive power suitable for light and frequent trains that, if operated by steam power, would be too costly to be profitable in such small units. So it has been in every field where electric power has been extensively applied. The most important result has not been a cheapening of work that was previously accomplished by other means, but more and better work has been accomplished, and so it will be with the use of electricity on railroads and this betterment will not be confined to railroading, because there is an interdependence in electric power operations, whereby any extension of electric lines and increased use of electric power for any purpose, leads to development of more and better electric power for all other purposes. How this must always result can be predicted by using a little justifiable imagination to clear the point of view of natural bias in favor of present conditions and methods that have gradually become unfavorable for present needs.

Custom and habit often leads to the continued use of apparatus and methods for work that could be better met by new means. To appreciate this, imagine that a wholly new country, that is destined by natural resources to become rich and prosperous, is to be opened up, settled and developed, and that some empire builder with a master hand and complete foresight could furnish the transportation and power facilities of the country. By means of electricity and the railroads, he could direct the development of the country. First of all, by building railroads with electric motive power, he would at once provide the means of 
transportation that is always adopted where the population is sufficiently dense. Following such lines of convenient transportation and power, population centers and settlements will naturally locate on the railroads with transmission lines along the roads; these various centers are tied together, forming the most efficient power system. If a country is to have a density of population and prosperity that would pay for transportation by electric roads, then the railroads should unquestionably be provided with transmission lines connecting the cities and these same transmission lines carrying electric power along the railroads, make the most economical means for distributing power for every purpose, and all the street cars, house lighting circuits, shops and factories along the railroad would naturally derive their power from these lines, and towns and manufacturing centers are always attracted by convenient power, as well as by good transportation conveniences. Then again, a diversified and extended use of electric power within any area increases the size of the power plants employed therein and accordingly reduces the cost of each unit of power generated.

A manager acting for a central power plant desiring to sell power to a city electric railroad system, recently put the matter as follows: To the banker president of the railroad, who has a reputation of being difficult to convince in any such matters as sacrificing or setting aside part of his property, the manager said "Do you want to make a dollar?" To which, after the way of bankers, he answered, "Yes." Then the manager asked him if he "would share the dollar with someone else who helped make it," to which he answered, "yes, if he could not make it all himself." Then said the manager, "I will sell you power for your railroad at less than it costs you to make it, and even so, I can make a profit on it, for you are making it in $2000-\mathrm{kw}$. units and I am making it in 6000-kw. units, and, therefore, at less cost than you are; but besides making it in larger quantities than you are, I am serving a great variety of companies and secure a more even and steady load than you do, since you are making power for only one kind of service, namely, to operate an electric railroad; but in addition to these reasons, I want your business, because with your load added to my present load I can generate power in $8000-\mathrm{kw}$. units, and still further reduce my kilowatt-hour cost."

It is not a matter of opinion but of accomplishment that available central station power is a valuable asset to every 
prosperous settlement, just as are railroads and telegraph and telephone systems. As power machinery and methods of work that are not now adapted to the electric plant are becoming obsolete or wearing out they are being supplanted by electric machinery, and electricity is being installed in new works where foresight is exercised to realize the maximum benefit by centralization and unification of power.

Much that was sought by railroads long before electric motive power was available for their needs is now accomplished with electricity. Years ago Wellington in his standard book entitled "Railroad Location "- - book by the way, that deserves a much more comprehensive title-pointed out that "In the sale of transportation, the price that the consumer is able and willing to pay is greatly affected by trifling differences of convenience." He emphasizes the importance of convenient local transportation facilities and says that "The loss to the railroad due to not supplying the best facilities might be borne if it meant simply a reduction of transportation tax upon the traveler or the shipper of freight," (in other words, less money paid to the railroad,) but he asks, "How stands it with the traveler or shipper? They save indeed the two or three cents per mile, which the railway loses, but they have to pay the entire cost of cartage on their freight and pay for their own conveyance besides suffering the annoyance and inconvenience, which they estimate at a good round sum." He says, "From poor transportation facilities, the loss is threefold: The cost to the public is greater. The receipts to the railroad are less. The traffic is decreased in volume." To quote still from Wellington, "This means from the point of view of political economy, and as a plain statement of fact, which would appear in census statistics, that the capital of the country and the world is less than it otherwise would be."

We can now add to Wellington's list of losses and state that poor transportation when resulting from failure of railroads to employ electric power under conditions favorable to its use will cause a fourfold loss, including the three losses enumerated and adding a fourth, represented by the added cost of power both for railroad working and for industrial uses, and in the fourth instance, as in the three enumerated by Wellington, this means from the point of view of political economy, a loss to allto the railroads and to the public alike.

While it has been one of the works of electric railroads to produce added values with better transportation facilities, it is not my intention to reiterate arguments for better local service 
with electric power as a means of increasing values. It is rather the purpose to accept the evidence of interurban railroads that electric power is advantageous for light and frequent train service, and from this premise to examine the conditions for its further application.

The general statements thus far made concerning central power supply and railroad operation are all capable of verification by examining specific conditions, but, as I indicated at the commencement of this paper, a complete analysis to apply to all conditions is most complex. It will be possible for me to give here only a few results based on actual operations which may be:used by those interested as a basis to compute what economy centralization and unification of power supply will secure at other places.

The figures given below are for the cost of producing electric power in steam plants carrying railroad loads under conditions that are widely prevailing in the United States. These figures are not exact costs taken from any particular power plant, but are average costs worked out from actual results in several steam plants on heavy railroad and other work, so shown as to permit easy analysis for varying conditions of load and for different fuel costs, etc.

\begin{tabular}{|c|c|c|c|}
\hline & $\begin{array}{l}\text { Total cost } \\
\text { per year }\end{array}$ & $\begin{array}{l}\text { Cost per year per kw. } \\
\text { of plant capacity }\end{array}$ & Per kw-hr. \\
\hline 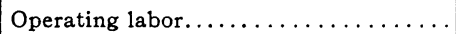 & $\$ 52,500$ & $\$ 2.10$ & 0.100 \\
\hline Operating materials (exclusive of fuel) & 15,000 & 0.60 & 0.025 \\
\hline Labor for maintenance of plant...... & 15,000 & 0.60 & 0.025 \\
\hline Material for maintenance of plant...... & 17,500 & 0.70 & 0.030 \\
\hline $\begin{array}{l}\text { Total cost of power plant, operation and } \\
\text { maintenance, exclusive of coal per yr. }\end{array}$ & $\$ 100,000$ & $\$ 4.00$ & 0.180 \\
\hline coal of 13,500 B.t.u. per pound. . . . & 82,500 & 3.30 & 0.15 \\
\hline 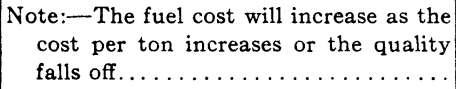 & & & \\
\hline $\begin{array}{r}\text { Other expenses pertaining to power plant } \\
\text { operation, such as administration, legal } \\
\text { and general expenses.............. }\end{array}$ & 10,500 & 0.42 & 0.02 \\
\hline & $\$ 193,000$ & $\$ 7.72$ & 0.35 \\
\hline 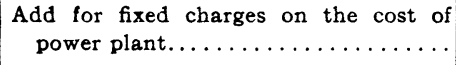 & 225,000 & 9.00 & 0.41 \\
\hline 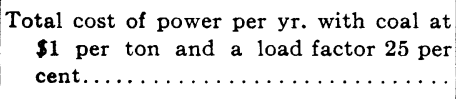 & $\$ 418,000$ & $\$ 16.72$ & 0.76 \\
\hline
\end{tabular}


The figures given are the cost, including fixed charges, of producing power in a $25,000-\mathrm{kw}$. steam-turbine plant, containing five main units of 5000-kw. nominal capacity each, but capable of carrying 50 per cent overload or more in emergencies.

The yearly production of power is assumed at $55,000,000 \mathrm{kw}-$ hr. or a load factor of 25 per cent on a maximum load of 25,000 $\mathrm{kw}$., which is the total nominal capacity of the five generators. It is equivalent to an average operation of all of the generators for 2200 hours per year at their rated capacity.

Such is the cost of electric power generation by steam for heavy railroad operation and general central station service.

There are two factors in the foregoing costs which are liable to maximum variations, viz., the cost of fuel and the average load on the plant, or as it is called, the load factor. The assumed maximum load of $25,000 \mathrm{kw}$. could easily be carried on four ordinary $5000-\mathrm{kw}$. nominal capacity steam-turbine generators, and leave one spare unit in a five-unit station. At 25 per cent load factor as assumed above $(25,000 \mathrm{kw}$. maximum load and 55,000 ,$000 \mathrm{kw}-\mathrm{hr}$. per year), the result in thermal efficiency would be about 8.4 per cent. It is difficult to determine from actual results just what the thermal efficiency would be at other load factors, but as it is sometimes necessary to know this as a basis for arriving at the fuel costs under varying load conditions, the following approximate figures are given for these variations. The coal is assumed to contain 13,500 B.t.u. per $1 \mathrm{~b}$.

\begin{tabular}{|c|c|c|c|}
\hline $\begin{array}{l}\text { Yearly load factor } \\
\text { (ratio of maximum } \\
\text { load to average } \\
\text { output) }\end{array}$ & $\begin{array}{c}\text { Average } \\
\text { operation } \\
\text { per yr., hours }\end{array}$ & $\begin{array}{c}\text { Thermal } \\
\text { efficiency of } \\
\text { plant }\end{array}$ & $\begin{array}{l}\text { Cost of coal per kw-hr. } \\
\text { at } \$ 1.00 \text { per short ton }\end{array}$ \\
\hline 10 per cent. & 876 & 6.5 per cent. & 0.20 cent \\
\hline $20 "$ " " & 1752 & $7.8 \ll$ & $0.16 \quad$ \\
\hline 25 « « & 2190 & $8.4 \leadsto$ & 0.15 \\
\hline 30 " & 2628 & $9 \quad$ " & 0.14 \\
\hline $40 " 4$ & 3500 & $9.8 \ll \quad$ & 0.13 \\
\hline $45 \quad$ " & 3940 & $10.1 \leadsto$ & 0.125 “ \\
\hline
\end{tabular}

It would be difficult to demonstrate in detail the economies that can be derived from combination of mixed power service from the above plant compared with power for only one industry like railroads, and an attempt at it would lead back to the same generalities that I have already stated, but analysis of the 
schedules of costs and thermal efficiencies for a 25,000-kw. plant, working at 25 per cent load factor, proves the broad assertion that in power generation large stations carrying mixed loads afford the maximum economies. Take, for example, the cost of general expenses and of fixed charges and of power station labor and material, exclusive of coal. These things are little affected by the load factor, but even in so large a station as $25,000 \mathrm{kw}$. they amount to $\$ 13.42$ per kilowatt per year, out of a total cost of power of $\$ 16.72$ per kilowatt per year, with good coal at $\$ 1.00$ per ton, or $\$ 20.02$ with coal at $\$ 2.00$ per ton, etc. Furthermore, even the fuel cost per unit of power generated will ordinarily be less in mixed service plants than on plants for railroad work only, since the former generally work at better load factors than the latter. The better load factor comes from serving a diversity of operations. Also with more operations the plant will be larger, and for this reason, as well, it naturally has a better load factor and all unit costs are correspondingly less.

There are other important advantages from centralization of power in large power plants, which will have important bearing on the future of central station business, for industrial and for railroad power. One of these has to do with obsolescence, and its importance in this connection does not always receive the attention that it deserves. Another is the utilization of offpeak or secondary power, which so far has been very little realized but which will increase in importance.

Obsolescence has long been the bugbear of electric companies that are striving to earn dividends, and centralization of power seems to be their best means of salvation. We all know that electric companies that were started fifteen or more years ago, whether they were for lighting or for railroads, or for whatever purpose, have found a large part of the cost of conducting their business has been due to the failure of apparatus to meet growing demands, not so much because it was worn out as because it became obsolete, when increasing business required larger powers and improved machinery.

Good serviceable power plants became obsolete because they could not do the increasing work of later years, and were discarded because the use of power increased. Centralized power plants meet changing conditions because they are built for larger service and constructed on a unit plan that can be economically extended to meet growing demands. 
The utilization of off-peak power will be promoted by the concentration at central points of large amounts of off-peak power, which can be more readily utilized as second-class power than the same amount of off-peak power if scattered through a number of small generating plants.

There are several very promising methods in prospect for utilizing off-peak or secondary power when it is concentrated in large blocks, but it is not within the scope of this paper to go into a discussion of them.

Next, turn to the power transmission side of the problem. In this the results in favor of large mixed operations are even more striking than in power generation. It is a difficult subject to generalize on, but briefly, suppose that a central plant is located at a favorable point at a coal mine or a water power, and it is desired to transmit power from the plant. It often pays to run 100 miles of transmission line to pick up a large load, whereas for a small load the cost of 10 miles of transmission may easily be too great. It follows that if the aggregate amount of power surrounding the power center is not large, it will not pay to go far for it, and the economical distribution area may be restricted to a radius of 10 miles or less. But on the other hand, if the aggregate is large, long-distance transmission will pay and the combination of large amounts of power per mile of transmission on long transmission lines, covering large areas, gives a big connected central station load. In this lies one of the great advantages in favor of including railroad roads on central plants, viz., where the amount of power and lighting scattered through a territory for manufacturing and similar purposes is not sufficient to make it economical to install electric transmission for this alone and where the railroad business is not sufficient to pay to transmit for railroad power alone, transmission for the combined loads will often be highly profitable.

There is a well-known power transmission company that affords an excellent example of the advantage of combining as much power as possible in a given territory. Its business aggregates something like 60,000 h.p., connected on several hundred miles of transmission lines, and the yearly cost of transmission, including all fixed charges and operation and maintenance of the transmission system, amounts to about $\$ 12.00$ per h.p. per year, based on its peak load of 50,000 h.p. Its load is industrial power and lighting with a few street railways. In the same territory there is a total consumption of power, exclusive of 
steam railroads, of approximately 225,000 h.p. which, if all served from a single central power plant, would produce a maximum load of probably 150,000 to 175,000 h.p., but for various reasons, one of which is the use of exhaust steam for heating buildings, factories, etc., the maximum load that it would be profitable to serve from the central plant would probably give peaks of only about 100,000 to 120,000 h.p., exclusive of steam railroad operation. The yearly cost of power transmission, including all fixed charges on transmission lines, for serving 100,000 h.p. in this territory instead of 50,000 h.p. maximum as now served, is estimated at $\$ 730,000$ total or $\$ 7.30$ per h.p. per year as compared with $\$ 12.00$ per h.p., which is the cost of power transmission and distribution for 50,000 h.p. only.

An examination of the steam railroad traffic in the same territory indicates that if all of the railroads used electric motive power exclusively, the railroad load would require a generating capacity of between 200,000 and 300,000 h.p., and if only the railroad lines carrying heavy traffic and frequent train service were electrified in the territory, the maximum load if served from a central station would be somewhere between 150,000 and 200,000 h.p., and that the yearly load factor of this railroad load, including freight and switching and passenger service, would be between 40 and 50 per cent. It is clear that if this load were added to the industrial and lighting load, it would greatly facilitate and cheapen the unit cost of distributing power from the central station.

In conclusion, I want to review briefly what the substitution of electric motive power for steam on existing railroads should include. It is not enough to say that it would require the construction of central station generating plants, of transmission and distribution lines, generally following the railroads. and of electric locomotives to replace steam. These would all have to be provided, of course, but that is not nearly all that should be done. Unless we look beyond such facts we cannot even appreciate the problem before us, much less solve it. When the railroads are paralleled by transmission lines over which central stations supply electric power for their operations, then the country traversed by the railroads will be in electric power zones, where power for any purpose may be taken from the lines along each railroad right of way and these lines will connect large central stations together, so that transmission lines will network the country as railroads now do and will connect 
important centers for power, as railroads do for transportation. Into this network of transmission circuits central electric plants will pump energy that can be drawn off in just the right amount to supply the needs of each point included in the network.

When this is carried out, the distribution of power, which is the greatest problem in the way of almost universal use of central station electric power, will be overcome with the resulting economy in generation as well as in distribution, since the most economical conditions for both generation and distribution are where large amounts of power are supplied at the best load factor attainable, which results when the largest number of operations are supplied from a single system. Thus there are many places where railroad electrification will be profitable, as outlined, where it would not pay to build transmission lines for the railroad load alone or for the industrial power and lighting without the railroad load. 